\title{
La agenda exterior de Biden y sus implicaciones para la Unión europea y América Latina
}

Anna Ayuso

\author{
aayuso@cidob.org
}

\author{
Recibido:12/07/2021. Aceptado: 25/07/2021 \\ CIDOB (España)
}

\begin{abstract}
Resumen: El artículo analiza las posibles consecuencias que tiene la nueva agenda exterior de Joe Biden para las relaciones hemisféricas y las relaciones transatlánticas. El regreso al multilateralismo y a un liderazgo activo de los Estados Unidos en el Sistema Internacional ofrece oportunidades para estrechar los lazos de cooperación, pero también comporta algunos riesgos dadas las crecientes tensiones que se están produciendo en la arena internacional, especialmente con el creciente activismo de China. Tras analizar las iniciativas que la Administración Biden-Harris ha tomado durante sus primeros 100 días en relación con América Latina y Caribe y con sus socios transatlánticos, el ensayo aboga por la necesidad de impulsar alianzas de geometría variable que ayuden a impulsar la gobernanza internacional, evitando dinámicas de confrontación.
\end{abstract}

Palabras clave: Estados Unidos, Unión Europea, América Latina, política exterior, China
* Cómo citar este artículo: Ayuso, A. (2021). La agenda exterior de Biden y sus implicaciones para la Unión Europea y América Latina. Relaciones Internacionales, 30(60), 134. https://doi.org/10.24215/23142766e134

Editor: Juan Alberto Rial, Instituto de Relaciones Internacionales Facultad de Ciencias Jurídicas y Sociales (Universidad Nacional de La Plata)
Entidad editora: Relaciones

Internacionales, es una publicación del Instituto de Relaciones Internacionales (Facultad de Ciencias Jurídicas y Sociales (Universidad Nacional de La Plata Argentina)

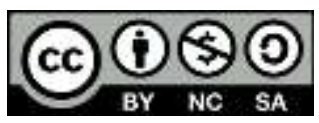

Reconocimiento-NoComercial Compartirlgual 4.0 Internacional (CC BY-NC-SA 4.0) 


\title{
Biden's foreign agenda and its implications for the European Union and Latin America
}

\section{Anna Ayuso ${ }^{1}$}

\begin{abstract}
The article analyzes the possible consequences of Joe Biden's new foreign agenda for hemispheric and transatlantic relations. The U.S. return to multilateralism and an active leadership in the International System offers opportunities to strengthen the ties of cooperation, but also carries some risks given the growing tensions that are taking place in the international arena, especially with China's growing activism. After analyzing the initiatives that the Biden-Harris Administration has taken during its first 100 days in relation to Latin America and the Caribbean and to its transatlantic partners, this essay advocates for the need to promote variable geometry alliances that may help promote international governance, thus avoiding confrontation dynamics.
\end{abstract}

Key Words: United States, European Union, Latin America, foreign policy, China

\footnotetext{
${ }^{1}$ Investigadora senior de CIDOB
} 


\section{Introducción}

Tras el revulsivo impacto que supuso la presidencia de Donald Trump en las relaciones transatlánticas, la llegada de Joe Biden a la Casa Blanca ha generado grandes expectativas de un cambio de estrategia internacional que va más allá de una vuelta al pasado. La Administración Biden-Harris se ha propuesto reconstruir la maltrecha relación con sus socios europeos, pero además busca recomponer la política hacia América Latina y el Caribe (ALC) para tratar de cicatrizar heridas del pasado. La renovación de ambas agendas abre una ventana de oportunidad para buscar puntos de acercamiento que permitan una mayor convergencia, no solo en el abordaje de las agendas birregionales, sino también en su contribución a la gobernanza global en un contexto de creciente complejidad y pugnas geopolíticas.

En el arranque de su legislatura, el nuevo presidente norteamericano se ha mostrado dispuesto a dar la batalla del multilateralismo y se propone ejercer un liderazgo activo frente a los grandes retos globales en los distintos foros y espacios internacionales que fueron abandonados o denostados por Trump, como el Acuerdo de París ${ }^{2}$ sobre cambio Climático o la Organización Mundial del Comercio (OMC). Este regreso de Estados Unidos a la escena internacional multilateral ofrece oportunidades para avanzar en la regulación de la gobernanza global, pero requerirá la formación de amplias alianzas tanto ALC como con la Unión Europea (UE).

Las primeras medidas que ha tomado Biden hacia ALC muestran una gran ambición en cuanto a los objetivos esperados, pero también surgen importantes obstáculos a sortear y constreñimientos tanto respecto a los recursos comprometidos como en las dificultades políticas internas. En el caso de las relaciones transatlánticas, Biden ha recuperado el compromiso con la Organización del Tratado del Atlántico Norte (OTAN) en el ámbito de la Defensa, que había sido cuestionado por Trump. Pero, sobre todo, ha dejado claro que espera mucho más de la relación con la UE en temas como el comercio, la crisis climática o la transición tecnológica, en los que busca aliados en la arena internacional.

Además, sin embargo, existen otros factores externos condicionantes que vienen de atrás. Tanto Estados Unidos como Europa han visto reducir su presencia e influencia en ALC frente a China en la última década. En América del Sur, el gigante asiático ha desplazado a la UE como mayor socio comercial y, cada vez más, como inversor. Estados Unidos también ha identificado la penetración de China en el continente como un factor de preocupación que se traslada a la geopolítica. El gobierno de Biden ve a China fundamentalmente como un competidor y no como un aliado, y está decidida a plantear una estrategia más comprehensiva y sistemática en diversos frentes (Pesek, 2021). Eso incluye el plano del poder militar (hard power), fundamentalmente por las tensiones en el Asia Pacífico, el plano económico y comercial, el tecnológico y también el ideacional (soft power). Así, el apoyo de China a países como Venezuela o Nicaragua se interpreta en Estados Unidos como un desafío y una amenaza a la democracia en toda la región. En eso no hay contro-

\footnotetext{
${ }^{2}$ https://unfccc.int/sites/default/files/spanish_paris agreement.pdf
} 
versia interna, ya que hay un acuerdo bipartidista entre demócratas y republicanos sobre la necesidad de dar una respuesta más asertiva hacia el creciente activismo de la potencia asiática en ALC (Piccone, 2020)

Sin embargo, la percepción de los riesgos y oportunidades que representa la creciente influencia China en el mundo no es idéntica en el espacio transatlántico, que se debate entre la cooperación y la competencia (Rubio Plo, 2021). Eso muy probablemente generará tensiones, tanto en las relaciones con la UE como con ALC, que se tendrán que lidiar en diversos frentes.

\section{Revitalización de la agenda hemisférica}

La presidencia de Donald Trump exacerbó las fracturas en las relaciones hemisféricas mediante políticas unilaterales y amenazas, incluso hacia aliados tradicionales, como Colombia o Chile, de las cuales no se salvó ni el presidente de Brasil, Jair Bolsonaro, quien le había expresado su adhesión incondicional. La lógica nacionalista y electoralista dominó la política de Trump hacia ALC y erosionó las instituciones hemisféricas, como la Organización de Estados Americanos (OEA), incapaz de llegar a consensos para responder a crisis políticas como la de Venezuela o Nicaragua, o el Banco Interamericano de Desarrollo (BID), donde impuso su candidato para la presidencia, Mauricio Claver-Carone, rompiendo así con la tradición de que fuera un latinoamericano el que lo liderara desde su fundación.

Sin embargo, aunque el mandato de Trump ha sido especialmente accidentado, desde hace varias décadas la política de los diferentes gobiernos de los Estados Unidos, republicanos y demócratas, hacia ALC ha venido decayendo. Se da la paradoja de que, por su proximidad e interrelación, las relaciones con la región están muy vinculadas a cuestiones domésticas, particularmente el tema de las migraciones y la seguridad ciudadana, que han dado lugar a la calificación de relaciones intermésticas, utilizando el concepto acuñado por Bailless Manning en 1977 (Long, 2017). Pero, por otra parte, las relaciones con la región no han sido una prioridad frente a otros focos de tensión que han concentrado la atención de su política exterior, como el terrorismo internacional, la inestabilidad en Oriente medio o la tensión geopolítica en el Asia Pacífico, a lo que se ha sumado la rivalidad con China.

Además, los giros de timón que ha tenido la política hemisférica de Estados Unidos tampoco ayudan a generar confianza. Si durante el gobierno de Obama, el entonces secretario de Estado, John Kerry, dio por terminada la Doctrina Monroe ${ }^{3}$ en un discurso ante la OEA en 2013, en 2018 el presidente Donald Trump la resucitaba ante la Asamblea General de Naciones Unidas ${ }^{4}$ mientras acusaba de injerencia a potencias extranjeras expansionistas. En realidad, el gobierno de Trump no tuvo una iniciativa regional estratégica, y se limitó a respuestas unilaterales y fragmentarias que, en lugar de crear cohesión, generaron más fragmentación en la región.

\footnotetext{
${ }^{3}$ https://www.wsj.com/articles/BL-WB-41869

${ }^{4}$ https://www.bbc.com/mundo/noticias-america-latina-45648320
} 
Al contrario que su predecesor, Biden conoce de antemano los problemas de América Latina y Caribe, una región que visitó dieciséis veces durante su vicepresidencia, especialmente a América Central. Pero se encuentra con una relación en sus horas más bajas en décadas y muy condicionada por la polarización política en la región. Entre las iniciativas que Biden tomó en sus primeros cien días se observa un gran interés por abordar los temas más candentes, como son la sempiterna crisis migratoria y la violencia en América Central, pero ha incorporado como puntos fuertes de la agenda temas como los Derechos Humanos y el cambio climático. El mandatario envía señales que muestran una voluntad de reconstruir puentes, pero algunos de los puntos calientes de la agenda no van a ser fáciles de gestionar, y las mayorías muy ajustadas en el Congreso y el Senado pueden suponer difíciles escollos para una acción ambiciosa dada la gran influencia que los lobbies internos tienen en la formulación de la agenda latinoamericana (Long, 2017).

Una de las primeras decisiones de Biden fue poner fin a las políticas de frontera lesivas para los derechos humanos de los migrantes, especialmente las relacionadas con menores y solicitantes de asilo. Eso ha mejorado la situación de los más vulnerables, pero no soluciona la crisis migratoria. De hecho, se ha observado un incremento de los flujos de entrada irregulares, lo cual ha hecho elevar el número de detenciones. ${ }^{5}$ Eso le ha validos críticas de varios sectores; por una parte, los republicanos acusan al presidente de que, con sus políticas más laxas, ha incrementado el "efecto llamada"; y, por otra parte, los defensores de los derechos humanos reprochan a la nueva administración el no atender debidamente las necesidades de los migrantes, especialmente los menores no acompañados, que han desbordado los albergues.

Biden está revirtiendo algunas políticas de Trump mediante decretos presidenciales, ha detenido la financiación del muro, ha facilitado el recurso a los servicios sociales de los inmigrantes, ha impulsado un programa para reunir a familias separadas y ha consolidado el Estatuto de protección temporal de venezolanos, birmanos o sirios. También ha presentado un proyecto legislativo al Congreso para la "Ley de Ciudadanía Americana de $2021{ }^{6}$ que pretende regularizar a 11 millones de indocumentados, brindar protección de los llegados en la Infancia o DACA (en inglés, Deferred Action for Childhood Arrivals) y reabrir las solicitudes de asilo en el territorio de Estados Unidos. Para algunas de esas medidas, no obstante, deberá contar con una mayoría calificada en el Congreso de la que, de momento, no dispone. Mediante decretos sí pudo hacer la rescisión de la declaración de emergencia en la frontera (aunque sin retirar las tropas) y la paralización de la financiación para el muro.

Pero la Administración Biden-Harris sabe que los problemas migratorios no son solo una cuestión de regulación de flujos. La crítica situación en la mayoría de países del istmo centroamericano, especialmente en el triángulo norte, con altas tasas de violencia y pobreza hacen imposible parar la huida de la población hacia el norte, azuzada por las mafias

\footnotetext{
${ }^{5}$ https://www.economist.com/leaders/2021/03/20/bidens-muddle-on-immigration

${ }^{6}$ https://iacoimmigration.org/ley-de-inmigracion-al-congreso-u-s-citizenship-act-of-2021/
} 
del crimen organizado. En 2014, como vicepresidente de Obama, Biden ideó una estrategia para apoyar reformas y reducir la migración irregular de centroamericanos, para la que obtuvo 750 millones de dólares en el Congreso con apoyo de demócratas y republicanos.

Tras nada más que jurar el cargo, esa volvió a ser una preocupación central y Biden anunció un Plan con Centroamérica de US\$ 4.000 millones para promover la seguridad y la economía. Al frente de la crisis centroamericana a puesto a su vicepresidenta Kamala Harris y a un equipo de apoyo, entre los que se encuentra el director senior para asuntos hemisféricos, Juan Sebastián González, de origen colombiano. Así, la primera gira internacional de la vicepresidenta fue a Guatemala y México el 7 y 8 de junio de 2021, con dos temas centrales: atajar la crisis migratoria, atendiendo las causas de origen, y ofrecer cooperación para abordarlas; pero también iniciar el combate contra la corrupción que, en su diagnóstico, es un obstáculo para el progreso de las sociedades centroamericanas. Al mismo tiempo, Harris quiso lanzar un mensaje claro sobre el mantenimiento de una política fuerte de control de fronteras con el slogan "Do not come" (no vengan), que enfatizo en la conferencia de prensa en Guatemala ${ }^{7}$

La lucha contra la corrupción se ha colocado como una de las principales prioridades y para ello han decidido apoyarse en organizaciones de la sociedad civil. La desconfianza hacia los gobiernos de la región lastra la colaboración con las instituciones y dificulta el apoyo a las reformas institucionales necesarias. A la presidencia de Daniel Ortega, que dura 14 años en Nicaragua, acusado de múltiples fraudes electorales, se ha sumado la deriva autoritaria de Nayib Bukele en El Salvador, quien, tras conseguir mayoría absoluta en el parlamento, ha arremetido contra las instituciones judiciales. Con el presidente guatemalteco, Alejandro Giammattei, la vicepresidenta Harris fue tajante en afirmar que el plan de ayudas está vinculado a reformas institucionales.

Más allá de Centroamérica, Biden encuentra una región que atraviesa una grave crisis institucional con amenazas a la democracia y los derechos humanos. Ya antes de la pandemia, hubo episodios graves de inestabilidad política con protestas, caídas de gobierno y elecciones cuestionadas, a lo que se añade la impunidad del crimen organizado y asesinatos de líderes comunitarios y activistas de derechos humanos. A ello se suma una economía en estancamiento y golpeada por el COVID-19, que -según la Comisión Económica para América Latina (CEPAL) de Naciones Unidas- ha provocado el incremento de la pobreza hasta niveles de dos décadas atrás y la profundización de las brechas de desigualdad (CEPAL, 2021). Un panorama poco propicio para dinamizar las relaciones hemisféricas, especialmente porque la relación de Biden con las dos potencias regionales, México y Brasil, no empezó con buen pie.

En el plano de las relaciones bilaterales EE.UU.-México, Trump usó un discurso confrontativo sobre el tema migratorio y el muro, con fines electoralistas. En materia comercial, señaló al Tratado de Libre Comercio de América del Norte (TLCAN) como "el peor acuerdo del mundo" y después usó la amenaza de subidas de aranceles para obligar a

\footnotetext{
${ }^{7}$ https://www.bbc.com/news/world-us-canada-57387350
} 
México a tomar medidas de vigilancia en la frontera. Pero en la práctica se llegaron a acuerdos con López Obrador: en el ámbito migratorio, se firmó un acuerdo en el que México se prestó a desplegar la Guardia Nacional en la frontera sur y a retener a los solicitantes de asilo en la frontera norte; y en el ámbito comercial, se firmó el nuevo tratado de Libre Comercio entre México, Estados Unidos y Canadá (T-MEC) aún bajo el mandato de Enrique Peña Nieto, que moderniza algunas cuestiones del anterior, pero no es tan diferente del que Trump había definido como nefasto, si bien es cierto que el nuevo acuerdo es más proteccionista frente a terceros Estados. A pesar de que se mantuvieran medidas unilaterales, como la declaración de emergencia realizada por Estados Unidos en febrero de 2019, que supuso un despliegue de tropas en la frontera, las relaciones entre Trump y López Obrador fueron fluidas.

Inicialmente, la tibia acogida por parte del presidente mexicano López Obrador del triunfo de Biden fue seguida de una relación distante y empañada por el rechazo expresado por el gobierno estaounidense a la política energética y ambiental mexicana. Sin embargo, las gestiones del secretario de Estado de Estados Unido, Antoni Blinken, y el posterior viaje de Kamala Harris muestran que ha imperado el pragmatismo debido a la interdependencia de las relaciones transfronterizas y se firmaron varios memorándums de entendimiento para impulsar la cooperación.

En el caso de Brasil, se daba por descontada la falta de sintonía con el presidente Jair Bolsonaro, declarado admirador de Trump; sin embargo, durante la cumbre climática virtual organizada por Biden en abril, el presidente brasileño prometió alcanzar la neutralidad climática para 2050 y acabar con la deforestación a cambio de financiamiento internacional. A presar de las dudas que suscita la voluntad de cumplir dichas promesas, no dejan de ser un síntoma de un cambio de posicionamiento de Bolsonaro frente a las presiones de la comunidad internacional ante un escenario menos favorable y crecientes dificultades internas. Pero Brasil, en la actualidad, sigue lejos de ejercer un liderazgo que contribuya al diálogo regional y esa percepción es compartida por Estados Unidos y la Unión Europea.

Hay dos puntos calientes en las relaciones con la región: Venezuela y Cuba, en los que Biden no ha tomado decisiones inmediatas y mantiene una cierta ambigüedad. En el caso de Venezuela, hay un reconocimiento de las limitaciones de las sanciones y del fracaso de la estrategia de cambio de régimen de Trump; sin embargo, Biden se muestra partidario de mantener la presión externa y el reconocimiento a la figura de Juan Guaidó como presidente encargado, así como fortalecer el estatuto de protección especial para los venezolanos en Estados Unidos. La Declaración Conjunta emitida por Estados Unidos, la Unión Europea y Canadá sobre Venezuela del 25 de junio de $2021^{8}$ refleja una loable voluntad de coordinar posiciones, aunque no supone un cambio sustancial sobre las posiciones respectivas.

En el caso de Cuba, las expectativas de un regreso a la política aperturista de Obama se han visto enfriadas por las declaraciones en las que Biden afirma no tener prisa en im-

\footnotetext{
${ }^{8}$ https://www.state.gov/translations/spanish/ee-uu-ue-canada-declaracion-conjunta-sobre-venezuela/
} 
plementar los cambios. Sin embargo, es más que probable que se establezcan negociaciones sin luz ni taquígrafos para avanzar evitando el ruido de los lobbies mediáticos de Florida, importantes para las elecciones de medio término de ambas cámaras del Congreso. Probablemente se hará un acercamiento gradual y vinculado a acontecimientos internos en la isla.

En el plano hemisférico, la negligencia de la atención norteamericana por la región, el discurso antimperialista que dominó entre los líderes del socialismo del siglo XXI en las primeras décadas del siglo, junto a la hábil diplomacia económica china han dejado mermada la influencia de Estados Unidos. Eso se ha reflejado en la debilidad de los instrumentos de cooperación regional, como la OEA o la Comisión Interamericana de Derechos Humanos, donde la polarización y fragmentación política han impedido tener un papel constructivo en la resolución de conflictos regionales. De hecho, Donald Trump no acudió a la única Cumbre de las Américas que se celebró durante su mandato en 2018, una cita que Barack Obama no descuidó en las tres ediciones que se celebraron durante su presidencia. Biden tiene la ocasión de escenificar una nueva etapa de las relaciones en la IX Cumbre de las Américas, en la que ejercerá de anfitrión durante el segundo semestre de 2021, y establecer las bases de lo que será la relación durante su mandato.

\section{La revisión de las relaciones transatlánticas en el eje norte.}

La presidencia de Trump sirvió de revolución para hacer una relectura de las relaciones transatlánticas, en las que quedó patente que alguna de las cosas que se daban por descontado habían cambiado. Ya el presidente Barak Obama dejó explícito el giro del eje de gravedad hacia el Pacífico (Nye, 2011). Aunque durante la Administración Obama-Biden se mantuvo el discurso de la alianza privilegiada con Europa, afloraron tensiones que iban más allá del reclamo estadounidense de un mayor compromiso europeo en el ámbito de la Defensa y el gasto militar. Lo expresó la canciller alemana Angela Merkel después de un encuentro del G7 en 2017 tras la elección de Trump y el abandono por parte de Estados Unidos del acuerdo nuclear con Irán: "Europa ya no puede confiar en EE.UU. y debe tomar su destino en sus propias manos"

El cuestionamiento de la vigencia de la Alianza por parte de Trump hizo saltar las alarmas. El 70 $70^{\circ}$ aniversario de la cumbre de la OTAN en 2019 fue el escenario en que se mostraron las diferencias sobre el futuro de la Alianza Atlántica. Ante las críticas de Trump, que cuestionó la misión de la OTAN y amenazó con retirar fondos, el presidente francés Emmanuelle Macron declaró que la organización estaba aquejada de "muerte cerebral"10. Sin embargo, lo cierto es que, en su conjunto, los países europeos incrementaron el gasto militar durante la presidencia de Trump, aunque ese era un compromiso que se acordó durante el mandato de Barack Obama (Biden, 2020).

\footnotetext{
${ }^{9}$ https://elpais.com/internacional/2018/05/10/actualidad/1525976998 891049.html

${ }^{10}$ https://www.france24.com/es/20191203-macron-trump-otan-criticas-terrorismo-presupuesto
} 
En su primera cumbre de la OTAN como presidente en junio de 2021, Biden quiso dejar en claro desde el principio su posición: "la OTAN es de vital importancia para los intereses de Estados Unidos y de sí misma. Si no hubiera una, tendríamos que inventarla"11. Sin embargo, hay también un cierto reconocimiento de que es necesaria una renovación para atender los nuevos desafíos, como los ciberataques, las amenazas híbridas, el uso disruptivo y dañino de las nuevas tecnologías y las campañas de desinformación.

Sin embargo, el tema fuerte que llevó Trump a la Cumbre fue la necesidad de dar una respuesta enérgica y concertada a las amenazas que representan China y Rusia en el ámbito geopolítico. Aunque Biden evitó una retórica de guerra fría, sí señalo claramente los peligros de acciones poco transparentes y agresivas en distintas partes del globo. También el secretario general de la OTAN, Jens Stoltenberg, quiso enfatizar que China "ya dispone del segundo mayor presupuesto militar y está invirtiendo en capacidades militares, y no comparte nuestros valores, lo vemos en cómo liquida las protestas democráticas en Hong Kong, en cómo trata a las minorías como los uigures, o cómo amenaza a Taiwán"12.

En el comunicado final de la Cumbre ${ }^{13}$ adoptado por los 30 mandatarios, se afirma que "[e]nfrentamos amenazas multifacéticas, competencia sistémica de poderes asertivos y autoritarios, así como crecientes desafíos de seguridad para nuestros países y nuestros ciudadanos." El documento dedica varios párrafos a condenar las que consideran conductas agresivas de Rusia sobre todo en Europa, pero también en otros lugares del mundo. Sin embargo, se apela al diálogo como forma de superar el enfrentamiento. Precisamente, al día siguiente tuvo lugar un encuentro entre Putin y Biden en Ginebra para descongelar unas relaciones, que están en niveles mínimos. No se esperaban grandes acuerdos y no los hubo, pero se evitó el enfrentamiento, manteniendo el más estricto estilo diplomático, y no se dio una rueda de prensa conjunta. Como medida de buena voluntad, se decidió restituir a los respectivos embajadores a sus puestos, mantener conversaciones en relación a los acuerdos de no proliferación nuclear e iniciar intercambios sobre seguridad cibernética.

Antes de la cumbre de la OTAN, tuvo lugar la Cumbre del G7 en Cornualles (Reino Unido), entre el 11 y el 13 de junio de 2021. La cumbre estaba centrada en concertar una respuesta a la crisis sanitaria aún en plena expansión en muchos lugares del planeta y en cómo establecer las bases de una recuperación sostenible que haga frente a los retos del cambio climático ${ }^{14}$. En el primer frente, se acordó la donación de 100.000 millones de vacunas, mayoritariamente a través del mecanismo COVAX de la OMS. Con ello se trata de

\footnotetext{
${ }^{11}$ https://cnnespanol.cnn.com/2021/06/14/joe-biden-llega-a-la-otan-para-su-primera-visita-comopresidente/

${ }^{12}$ https://elpais.com/internacional/2021-06-14/biden-quiero-que-la-otan-sepa-que-estados-unidos-estaahi.html

${ }^{13}$ https://www.nato.int/cps/en/natohq/news 185000.htm

${ }^{14}$ https://www.consilium.europa.eu/es/meetings/international-summit/2021/06/11-13/
} 
contrarrestar la diplomacia de vacunes que han desplegado tanto Rusia como China proporcionando vacunas a países en desarrollo, mientras la Unión Europea y Estados Unidos parecían más ocupados en acaparar vacunas para su uso interno. A pesar de que hubo donaciones previas por parte de Europa a la OMC, diversos países del Sur, incluida América Latina, se ha criticado la falta de solidaridad de las potencias más ricas. Los líderes del G7 también se comprometieron a involucrarse en las conversaciones sobre la propiedad industrial en la OMC, con la finalidad de levantar los derechos de patente temporalmente para hacer frente a la pandemia. Biden se había manifestado favorable, pero no hay consenso entre el resto de los países del grupo, incluidos los europeos.

En cambio, sí se aprobó la implementación de una de las propuestas que Biden había hecho por adelantado: la creación de un impuesto mínimo a las grandes corporaciones del $15 \%$ como forma de conseguir recursos adicionales para la recuperación y evitar la competencia desleal de esas transnacionales frente a las industrias nacionales.

Frente al bloqueo del sistema multilateral del comercio en la OMC y la guerra comercial que protagonizó Trump los líderes del G7, se han puesto de acuerdo en la necesidad de adoptar una visión común para la reforma del sistema multilateral de comercio, cuyos pilares centrales sean un código normativo modernizado y una OMC reformada. También se destacó la importancia de que la función negociadora y el sistema de solución de diferencias de la OMC funcionen adecuadamente, frente al bloqueo que ejerció el gobierno de Trump al negarse a elegir a los jueces que terminaban su mandato. Pero al mismo tiempo se señaló, respecto a China, que se buscarían respuestas colectivas frente a las políticas y prácticas no sujetas a las leyes del mercado que socavan el funcionamiento equitativo y transparente de la economía mundial y a la libre competencia. La transición ecológica y la financiación de la lucha contra el cambio climático también fueron objeto de propuestas dentro de los vigentes acuerdos internacionales una vez reintegrado Estados Unidos al Acuerdo de París.

Muchos de los debates entre las grandes potencias giraron en torno a los regímenes internacionales y el conjunto del orden internacional. Europa y Estados Unidos estaban acostumbrados a ser rule-makers, pero esa potencia normativa se está viendo contestada y erosionada -y no solo por China y Rusia, también Trump en su momento contribuyó al debilitamiento del sistema multilateral. Otra consecuencia del cuestionamiento de los valores es la pérdida de influencia en la opinión pública que lleva a una relativización de los valores compartidos por el bloque occidental, lo cual pone en peligro el orden liberal. La elección de Biden ha devuelto a Estados Unidos a una posición de liderazgo, pero necesita de aliados y en Europa y América cuenta con sus principales socios tradicionales, junto con Japón y Australia.

\section{Escenarios para la reconstrucción del multilateralismo en clave geopolí- tica desde una nueva perspectiva transatlántica y hemisférica.}

Aunque la elección de Biden fue acogida con grandes esperanzas por los aliados hemisféricos y transatlánticos, muchas de las tensiones que afloraron durante el mandato de Trump tienen raíces previas y no desaparecerán de un plumazo. Sí se espera, sin embargo, 
que cambie la forma en la que se afronten los conflictos. Biden ha dicho que Estados Unidos ha vuelto al multilateralismo, pero lo hará de forma asertiva, para defender sus intereses y los de los ciudadanos de Estados Unidos, así como los valores que están en la base de su sistema político (democracia y derechos humanos). Así se lo hizo saber a Putin, a sus socios en la OTAN y el G7, y a los socios latinoamericanos y caribeños.

Si algo ha cambiado en el mundo en la última década es la visión que Estados Unidos y Europa tienen de China. El auge del gigante asiático, su penetración en distintos ámbitos geográficos y su creciente activismo en instituciones internacionales (Otero-Iglesias, 2020) han sido más determinantes de ese cambio de visión que la errática estrategia de Trump. Biden ha planteado claramente en relación con China, en términos de competencia sistémica entre las democracias y las autocracias (Wright, 2021). Sin embargo, el actual grado de interdependencia económica en diferentes ámbitos también obliga a una aproximación pragmática y a buscar alianzas.

Hoy en Europa, nadie duda de que China es un "rival sistémico" (Bregolat, 2021); no un enemigo, pero sí un competidor que trata de cambiar las reglas del juego. Ya en el documento de estrategia que en marzo de 2019 remitió Federica Mogerini, Alta representante para la Política Exterior y Seguridad de la UE, a las instituciones europeas ("UE-China. Una perspectiva estratégica"15) se definía una relación poliédrica: "China es, al mismo tiempo, en distintas áreas, un socio cooperador, con el cual la UE tiene objetivos estrechamente alineados, un socio negociador, con el que la UE tiene que encontrar un equilibrio de intereses, un competidor en la búsqueda del liderazgo tecnológico, y un rival sistémico que promueve modelos alternativos de gobernanza". Por ello el mismo documento señalaba que las herramientas y las modalidades de la cooperación de la UE con China deben diferenciarse en función de las políticas en diferentes ámbitos y sectores políticos a fin de ejercer más influencia en la consecución de sus objetivos, para lo que pedía unidad y coherencia del conjunto de los Estados miembro.

La relación de América Latina y China también ha evolucionado rápidamente en la última década. Aunque Estados Unidos sigue siendo el mayor socio económico para una buena parte de la región, sobre todo México, su presencia está siendo erosionada por la penetración de China, que ha incrementado su comercio en más del $200 \%$ durante la última década. La presidencia de Trump reaccionó con amenazas y la imposición unilateral de tarifas a las exportaciones, incluso a aliados como el Brasil de Bolsonaro (también lo hizo con la UE). Biden es menos agresivo y ha cambiado el slogan "América First" por "Buy American", pero no parece probable que renuncie a las barreras comerciales. Los principales socios de China en América del Sur son conscientes de que necesitarán de la demanda de China como motor para la recuperación post COVID-19. Sin embargo, también entienden los peligros de una excesiva dependencia (Picone, 2020). Además, la pandemia de COVID-19 ha incrementado la sensación de vulnerabilidad al mostrar la dependencia de las cadenas de suministros.

\footnotetext{
${ }^{15}$ https://ec.europa.eu/info/sites/default/files/communication-eu-china-a-strategic-outlook es.pdf
} 
Así, pues, el escenario internacional que se proyecta es de gran complejidad en el que la competencia sistémica entre China y Estados Unidos se entrelaza con la necesidad de cooperar en distintos ámbitos. El alineamiento incondicional a un bloque no es una opción viable, ni para Europa ni para América Latina. Eso obliga a una estrategia marcada por una geopolítica de geometría variable.

En el ámbito económico habrá que ver cómo se desarrolla el regreso de Estados Unidos al sistema multilateral. Durante el mandato de Trump, el abandono del Tratado Transatlántico de Comercio e Inversiones (TTIP por sus siglas en inglés), el bloqueo de la OMC y las medidas unilaterales contra productos europeos, con la acusación a Europa de mala fe, llevó a la Unión Europea a la intensificación de las negociaciones bilaterales y birregionales con otros países, como Canadá y Japón, y con Mercosur en ALC; aunque la ratificación de este último está en peligro a causa de la oposición de varios países de la UE, los que alegan la falta de compromiso con la lucha contra el cambio climático por parte de Brasil. Esto pone en peligro un instrumento fundamental para fortalecer la cooperación interregional avanzar en la consolidación de un marco regulatorio internacional que contribuya a una gobernanza global del comercio más transparente.

La OMC lleva dos décadas en crisis y para sacar de la parálisis la Ronda de Doha, será necesaria una reforma con unas normas que sean admisibles tanto para Washington como para Pekín y para los países en desarrollo. La UE y ALC deberían tener la capacidad de situarse en una posición conciliadora (Otero-Iglesias, 2020) que les permita mantener los intercambios con China, pero que garantice una transparencia del sistema y la protección de unos estándares internacionales. El tema de la liberalización aduanera no va a ser el protagonista, porque las tendencias proteccionistas no van a desaparecer con Biden. Serán los temas regulatorios los que tengan más peso, incluidos los estándares ambientales. En el ámbito de la propiedad intelectual es probable que China pase a ser un aliado, dada la apuesta que está haciendo por la innovación tecnológica. Sin embargo, lo que ha surgido es una competencia en torno a la tecnología G5, en la que ALC y la UE se han encontrado en un fuego cruzado. Se debería tratar de evitar entrar en una dinámica de bloques en competición y destinar recursos adicionales para fomentar un acceso equitativo a toda la población, contribuir a la regulación del uso de las tecnologías y garantizar los derechos de las personas en el entorno digital.

La lucha contra el cambio climático también ofrece oportunidades de un diálogo constructivo entre Estados Unidos y China, que puede potenciar importantes avances en las metas del Acuerdo de París en el que la UE y ALC pueden salir fortalecidas. Pero también existen riesgos de una batalla tecnológica en todo el proceso de transición energética. Además, la transición energética también precisa mejorar las medidas regulatorias, tanto internas como internacionales, que garanticen una mayor transparencia y aseguren el cumplimiento de las metas establecidas en el ámbito internacional en favor de la protección del medio ambiente. Así, iniciativas como el «Acuerdo regional sobre el acceso a la información, la participación pública y el acceso a la justicia en asuntos ambientales en América Latina y el Caribe» (Acuerdo de Escazú), que entró en vigor en abril de 2021, y el convenio sobre el «Acceso a la información, la participación del público y a la justicia en materia de medio ambiente» de la UE (Convenio de Aarhus), vigente desde el 30 de octu- 
bre de 2001, pueden contribuir a fortalecer un marco normativo global en favor de la aplicación del Principio 10 de la Declaración de Río sobre Medio Ambiente y Desarrollo.

En el ámbito de la seguridad, la Europa post Brexit va a tener que revisar su estrategia. Habrá que recomponer el encaje de las piezas Estados Unidos, Reino Unido y UE dentro y fuera de la OTAN. Europa va a tener que asumir más responsabilidad, más gastos, más coordinación y mayor capacidad operativa. ALC, tras la crisis de UNASUR y las tensiones en la OEA, también precisa redefinir los espacios de cooperación regional e interregional. Igualmente están en redefinición cuáles son los verdaderos retos de la seguridad en el siglo XXI y la forma en que se les debe hacer frente, cómo se puede actuar ante a las amenazas hibridas, los ciberataques y la creciente violencia del crimen organizado. Es necesario rediseñar las estructuras e instrumentos internacionales de cooperación.

Ante el actual contexto de redefinición del orden global, en el cual se está redimensionando el rol de los actores internacionales, la llegada de Biden y su retorno al multilateralismo ofrece oportunidades para actores como la UE y los países de ALC, que buscan un posicionamiento estratégico que les permita el mayor espacio posible de autonomía $y$, al tiempo, una reducción de su vulnerabilidad ante la creciente interdependencia global establezcan alianzas para influir en la gobernanza de los retos globales. Una respuesta a estos retos es definir asociaciones estratégicas de geometría variable y flexible con otros actores, como, por ejemplo, fortalecer la alianza entre la Unión Europea y la Comunidad de Estados Latino-Americanos y Caribeños (CELAC) como espacio interregional intermedio que contribuya a balancear las dinámicas de confrontación bipolar que solo agravarían las asimetrías de poder. La nueva orientación que Biden quiere dar a la agenda hemisférica y la transatlántica ofrece una oportunidad para coordinar posiciones que contribuyan a un sistema internacional renovado, reforzado y más equilibrado en el que prevalezca la cooperación sobre la confrontación.

\section{Referencias.}

Ayuso, A. (2021) “Claves para reactivar la asociación UE-CELAC y encauzar la globalización del futuro" Notes Internacionals CIDOB no 247, 03/

https://www.cidob.org/publicaciones/serie de publicacion/notes internacio nals cidob/247/claves para reactivar la asociacion ue celac y encauzar la globalizacion del futuro

Bregolat, E. (2021) "Socio, competidor y rival sistémico" Política Exterior 199 https://www.politicaexterior.com/articulo/socio-competidor-y-rivalsistemico/

Biden, J.R. Jr (2020) "Why America should lead again. Rescuing U.S. Foreign Policy after Trump" Foreign Affairs, March-April.

https://www.foreignaffairs.com/articles/united-states/2020-01-23/whyamerica-must-lead-again

CEPAL (2021) “Panorama social de América Latina 2020”, CEPAL, Santiago de Chile marzo 2021, p. 262. 
Kleine-Brockhoff, T. "Joe Biden's 100 days of Solitude" The German Marshall fund of the United States, April 29, 2021 https://www.gmfus.org/blog/2021/04/29/joebidens-100-days-solitude

Long, T. (2017) “Coloso fragmentado: la agenda "interméstica" y la política exterior latinoamericana." Revista Foro Internacional 227 no 1 enero-marzo 2017 p. 5-54

Manning, B. (1997) "The Congress, the Executive and Intermestic Affairs: Three Proposal" Foreing Affairs, January 1977

Moreira, C. (2021) “América Latina: Joe Biden y después." Latinoamerica 21, 5 enero. https://latinoamerica21.com/es/america-latina-joe-biden-y-despues/

Nugent, C and C. Campell (2021) "The US and China are Battling for Influence in Latin America, and the Pandemic has Raised the stakes." Time, February 4 https://time.com/5936037/us-china-latin-america-influence/

Nye, J.S Jr (2011) "El giro de Obama hacia el Pacífico" Project Syndicate. The World's Opinion Page December 6. https://www.project-syndicate.org/commentary/obama-spacific-pivot/spanish

Otero-Iglesias, M. "China y la Unión Europea: de socios estratégicos a rivales sistémicos" en García-Duran, P y E. Serrano (eds) "Geopolítica y Comercio en tiempos de cambio. Una mirada desde Barcelona" Monografías CIDOB no79 12/2020, pp. 73-80

Pesek,W. (2021) “China Missing Troump Terribly As Biden Hits hard power" Forbes, May 28 https://www.forbes.com/sites/williampesek/2021/05/28/china-missingtrump-terribly-as-biden-hits-hard-power/?sh=7b6bad5f7a5f.

Piccone, T. (2020) "China and Latin America: A pragmatic embrace" Global China Serie, Brookings Institution. https://www.brookings.edu/research/china-and-latinamerica-a-pragmatic-embrace/

Rubio Plo, A.R. (2021) “Europa entre Estados Unidos y China” Blog Real Instituto Elcano 27 Marzo 2021 https://blog.realinstitutoelcano.org/europa-entre-estadosunidos-y-china/

Serbín, A (2021) "El Indo-Pacífico y América Latina en el marco de la disputa geoestratégica entre Estados Unidos y China" Documentos de trabajo no 45 2a época. Fundación Carolina.

https://www.fundacioncarolina.es/wpcontent/uploads/2021/04/DT_FC_45.pdf

Smiled, D. (2021) “Trump's bluster failed Venezuela. Biden must use diplomatic and economic levers to address the crisis" The Washington Post 20 enero 2021. https://www.washingtonpost.com/opinions/2021/01/19/venezuela-bidenmaduro-guaido-trump-diplomacy/

Wright, T (2021) "Joe Biden worries that China might win" The Atlantic, Brookings 9 June 2021 https://www.brookings.edu/opinions/joe-biden-worries-that-china$\underline{\text { might-win/ }}$ 